\title{
Design, synthesis, and manufacturing of a competitive, lightweight, space-frame, open wheeled, single seated all-terrain vehicle (ATV)
}

\section{Original Article}

\author{
Mostafa Asfoor, Mostafa Yacoub
}

Automotive Engineering Department, Military Technical College, Cairo, Egypt

\section{Keywords:}

All-terrain vehicle, space frame, inverted ackerman, anti-dive, anti-squat, active learning tool.

\section{Corresponding Author:}

Mostafa Asfoor, Automotive Engineering Department, Military Technical College, Cairo, Egypt. Tel: +201142761111, Email: asfoor@mtc.edu.eg

\section{Abstract}

The process of designing a vehicle isn't a simple task. The procedures of designing a safe, reliable, high performance, lightweight, spaceframe, and single seated All - terrain vehicle (ATV) through applying the necessary scientific tools, engineering knowledge, and skills are highlighted in this work. An ATV was designed according to specific rules predefined by the Society of Automotive Engineering (SAE) board to ensure a high level of safety during the execution of different steps. The project was created with the idea that the best way to learn engineering is by doing engineering, where the vehicle described in this project is the result of the integration of several junior and senior engineering design projects. An innovative steering system design is introduced, including mathematical optimization of an inverted Ackerman steering system linkages. Experimental testing of suspension system components took place, and for improving ride comfort, anti-dive and anti-squat mechanisms were implemented. The vehicle was designed mainly for endurance purposes, so more attention was drawn to components' durability and frame rigidity to sustain the severe conditions of stress arising from typical off-road driving obstacles (sand, mud, gravel, stone, dirt,...etc.), in addition to driver comfortability to secure sustainable driving as much as possible on rough terrains.

\section{INTRODUCTION}

Design and manufacture of a low-cost ATV requires special management of resources and utilization. Among all challenges, one is of prime interest, considering local manufacturing capabilities, especially for prototyping. The SAE BAJA competition is considered a remarkable milestone in the design and low-cost manufacture of vehicles, which started in 1976 to encourage engineering students to collect teams to design and manufacture lightweight ATVs to compete in a real field environment ${ }^{[1]}$. Teams from all over the world are competing annually to produce reliable ATVs. Since this competition targets engineering faculties and students, the challenge of managing to build a reliable low-cost prototype is one of the remarkable outcomes to credit this competition. Some teams have recorded an interesting design procedure for ATVs.The most common design methodology used by the teams was the V-Model approach. Although this methodology enhanced the ATVs performance, the need to further optimize the manufacturing costs was debatable $e^{[2,3]}$. Several attempts were addressed in the literature. Sandeep Chaudhaey et al. introduced a design analysis and manufacturing procedure of a lightweight $\mathrm{ATV}^{[4]}$. The authors focused on a light but rigid and ascetics oriented frame taking into consideration the robustness of the suspension system, where they succeeded in producing a competitive prototype.Yogesh Chandra analyzed and optimized the design parameters of a space frame using ANSYS and ALTAIR Hyperworks ${ }^{[5]}$. Anthony Taylor Owens et al. suggested an enhancement to the vehicle to reduce weight, and hence improve performance ${ }^{[6]}$. Yogesh Sharma et al. followed a noticeable methodology for students learning by implementing a hands-on engineering project to apply engineering science in designing and manufacturing a light $\mathrm{ATV}^{[7]}$. Considering powertrain the heart of the project, Rishabh Jain and Ranjit designed a drivetrain taking into consideration performance parameters as gradeability, acceleration, and $\mathrm{NVH}^{[8]}$. The primary target Akshay Bodake et.al. decided was to minimize as much weight as possible in the powertrain system by cutting off unnecessary masses, and packaging the transmission to the most compact possible size ${ }^{[9]}$, while Perez, S. and Bachman, J., objectives were to design and build a drivetrain that provide the lowest time to reach the highest possible top speed ${ }^{[10]}$. Suspension system is of extreme importance for load transfer to the wheels and driver protection against road shocks. Akshay G. Bharadwaj et al. designed, optimized, analyzed, and validated the suspension system for an ATV ${ }^{[11]}$. Double 
wishbone is a common suspension type used in such ATV, where independent wheel movement gives a great capability of navigating on bumpy uneven road as discussed by Nayan Deshmukh et al. ${ }^{[12]}$. ATV direction control via the steering system is considered the most influencing subsystem in designing a competitive vehicle, for that reason several researchers had introduced the design procedures, analysis, and optimization of different aspects regarding vehicle handling characteristics. Akshay Pawar, and Suraj Zambare discussed the steering system design requirements for an $\mathrm{ATV}^{[13]}$ and S. Neelakrishnan et. al. analyzed the steering characteristics of an ATV ${ }^{[14]}$, also Alfred Showers and Ho-Hoon Lee performed a complete design procedures using Ackermann principle ${ }^{[15]}$, while Asad Khan optimized the design parameters of a rack and pinion steering system to enhance weight reduction ${ }^{[16]}$.

Simulating a real-world engineering design project and its related challenges could act as an active learning tool that helps facilitate a linkage between engineering theory and engineering practice. The main contribution of this work was to design and build an off-road vehicle that will survive in severe conditions of rough terrain. The project progress started from the conceptual design phase to a complete functional vehicle that meets all of the safety, performance, and other criteria required for such types of vehicles. The project tasks provide valuable hands-on experience, planning, and manufacturing knowledge over different subsystems of the vehicle. Scheduled tasks had been established to control the procedure's timeline for design and manufacturing using a "Gantt Chart". The challenges associated with this project expanded local design analysis as well as advanced manufacturing infrastructure. The methodology used in this work highlighted system integration, and design concepts, followed by four sections discussing the design, manufacturing, and testing of the different subsystems that had been conducted to build the aforementioned vehicle. The conclusion section summarizes a two-year of hard work.

\section{METHODOLOGY}

Since the conceptual definition ought to consider partial conflicting boundary conditions between subsystems encountered by multi-developers, the resulting vehicle concept was represented by an outcome of twodirectional continuous optimization processes as shown in Figure 1. To guarantee a valuable detailed data outcome from the system integration in the early phases of design, a centralized Three Dimensional Computer-Aided Design (3D-CAD) model was considered. Thanks to design Tables

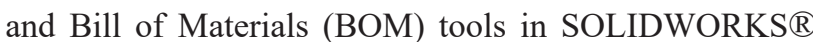
which enabled linked Excel data sheets of the design parameters (inputs and outputs) of the overall assembly, the individual subassemblies, and individual parts. This allowed for the existence of a repository of Excel data sheets (for dimensions calculations), BOM (for mass properties calculations), and a centralized master 3D-CAD model. This facilitates the synchronization use and update of individual system design, according to the performance calculations, and easily integrates into the whole vehicle design concept. This way, the integration included linking Computer-Aided Engineering (CAE) packages together like SOLIDWORKS ${ }^{\circledR}$, Finite Element Analysis (FEA), Computational Fluid Dynamics (CFD), MATLAB, and Excel. The aforementioned methodology proved to achieve remarkable progress in the integration between the subsystems.

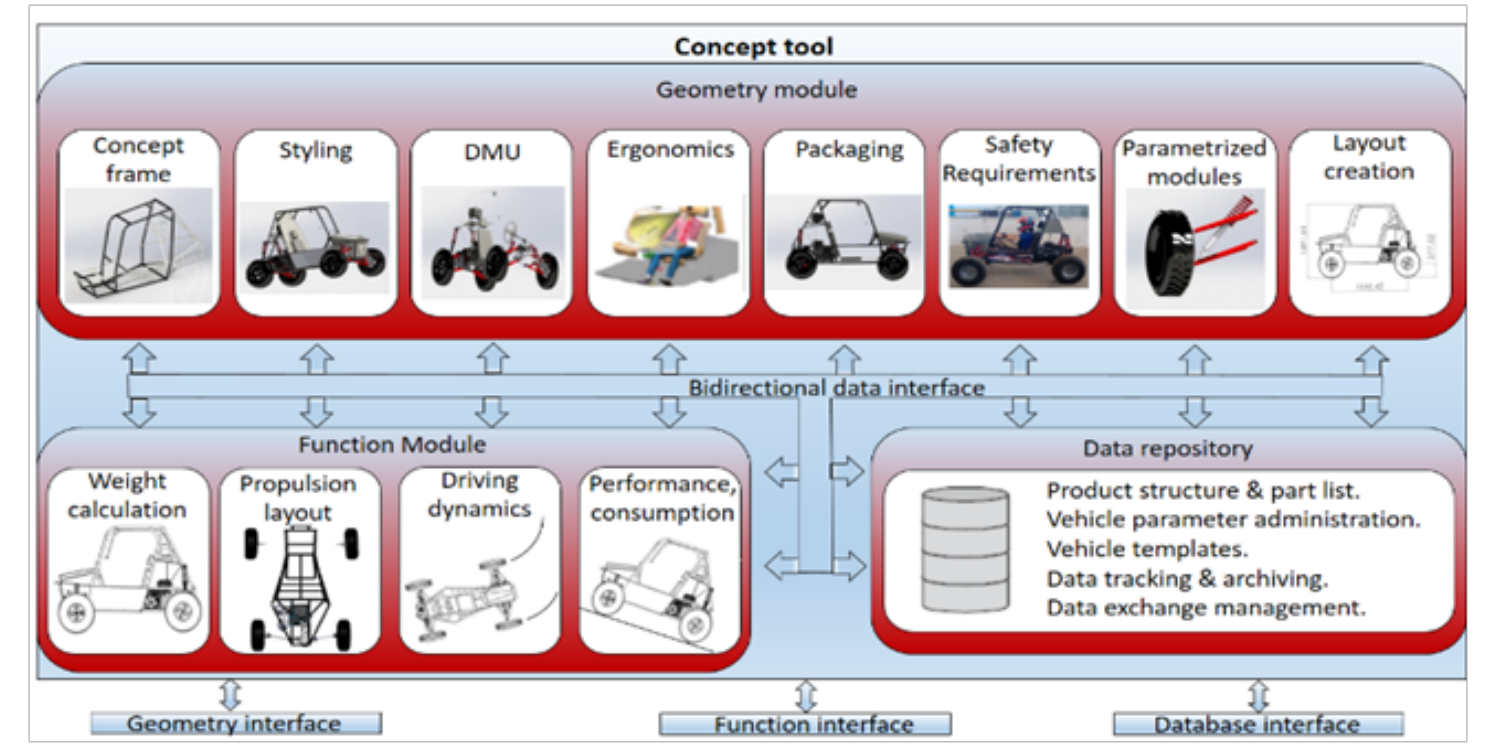

Fig. 1: System integration scheme and design concept 


\section{FRAME AND ERGONOMICS}

For these types of vehicles, the space frame is the most usable type of frame. It was necessary to create a driver envelope and a region of reachability that would not only fit the proposed drivers in place but also would allow comfort, safety, and accessibility to driving controls. In addition, safety features were considered to accommodate for different emergency situations.

Some of the major ergonomic factors considered were seat location and inclination, fixation points of the driver harness and its inclination angles to snug across the driver's pelvic area below the Anterior Superior Iliac Spines (the hip bones), the location and dimension of the steering wheel, location and design of the pedal assembly, location of an engine kill switch, the space required to egress in maximum five seconds in emergency situations, and finally, the visibility of the driver. The cockpit was designed to fit all adult human body sizes ranging from $95^{\text {th }}$ percentile male to the $5^{\text {th }}$ percentile female according to SAE standard ${ }^{[17,18]}$

ASTM A106 grade B with carbon content (0.19:0.20) was selected as the frame material. For the primary members, both the diameter and thickness have been selected to be $33.4[\mathrm{~mm}]$ and $3.38[\mathrm{~mm}]$, respectively, while the secondary members were $26.7 \quad[\mathrm{~mm}]$ and $2.76[\mathrm{~mm}]$, respectively. The overall dimensions of the frame were $2130[\mathrm{~mm}]$ long, $830[\mathrm{~mm}]$ width, and $1200[\mathrm{~mm}]$ height as shown in Figure 2. The net weight of the frame was $70[\mathrm{~kg}]$. Bending stiffness and strength analyses were performed relative to the standard 1018 steel.

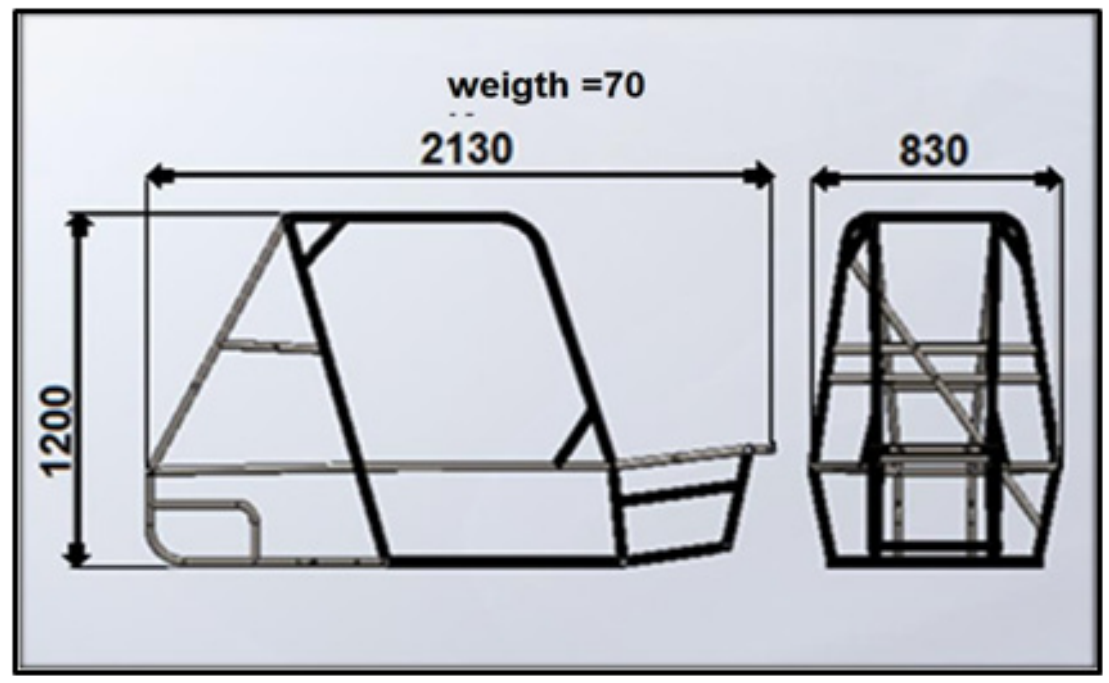

Fig. 2: Frame main dimensions

During normal driving there is a significant risk of rollovers, falling from steep edges, collisions with stationary objects, or impacts from other vehicles. Frame analysis was accomplished using SOLIDWORKS ${ }^{\circ} F E A$. Several simulation tests were carried out to ensure sufficient factors of safety for the frame including impact, torsion, towing, and rollover simulation tests. Each impact simulation test represents a typical scenario that could be potentially encountered during different driving situations. All the impact forces were simulated with their equivalent static forces (i.e. impulse time intervals, $t$, were included). For the drop test, the vehicle was subjected to a free fall from a height (h) of 2 [m]. The impulse force is given by equation (1).

$$
F=\frac{m \sqrt{g h}}{t}
$$

Front-impact collision simulation results are shown in Figure 3.The simulation represents a head-on accident with a relative velocity of $20[\mathrm{~km} / \mathrm{h}]$. The rear-end crash represents the case where a moving $350[\mathrm{~kg}]$ vehicle hit the vehicle rear end with a relative velocity of $20[\mathrm{~km} / \mathrm{h}]$. The side impact simulation is shown in Figure 4, representing the effect of hitting the side of the vehicle by a moving $350[\mathrm{~kg}]$ vehicle with a velocity of $20[\mathrm{~km} / \mathrm{h}]$.

For the impact simulation test, equation (2) was used to calculate the force $(\mathrm{F})$ applied to the vehicle using an impulse time $(\mathrm{t})$ of $0.2[\mathrm{~s}]$. The simulation results showed that the factor of safety for the head-on accident was 1.6, the factor of safety for the rear-end crash was 3.3 and the side impact was 2.4. During each analysis, the areas of high stress were concentrated on and alleviated by adding bracing members to tune the stiffness and redistribute the load to other areas.

$$
F=m \Delta v / \Delta t
$$

To find the torsional stiffness of the frame, a 1000 $[\mathrm{N}]$ vertical force was applied to one of the wheels while maintaining the other three wheels fixed. As shown in Figure 5, the torsional stiffness was 4.2 [kN/deg]. 


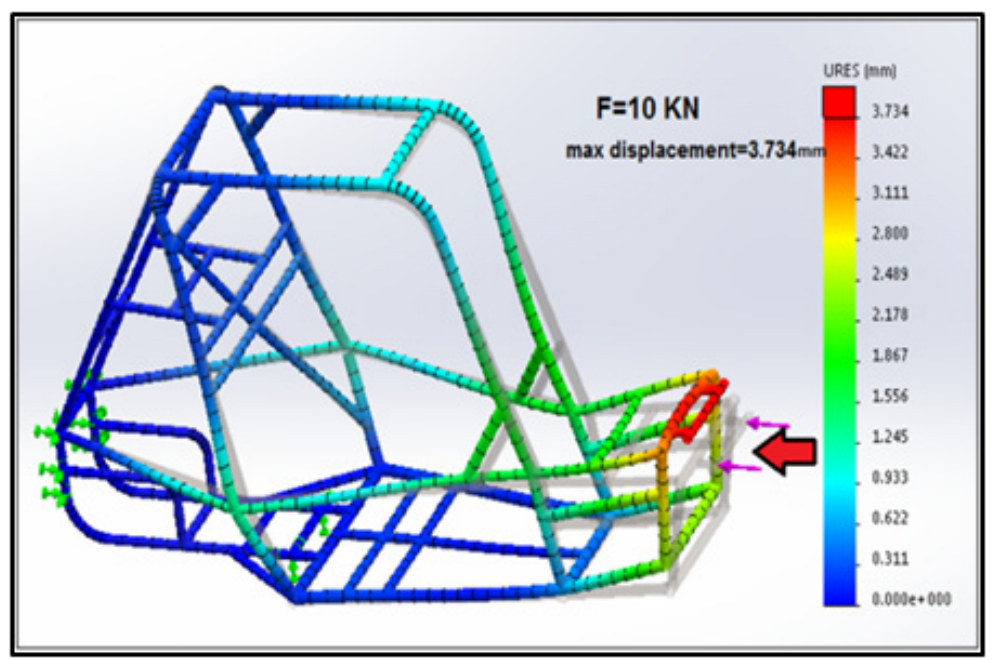

Fig. 3: Frontal collision stress analysis

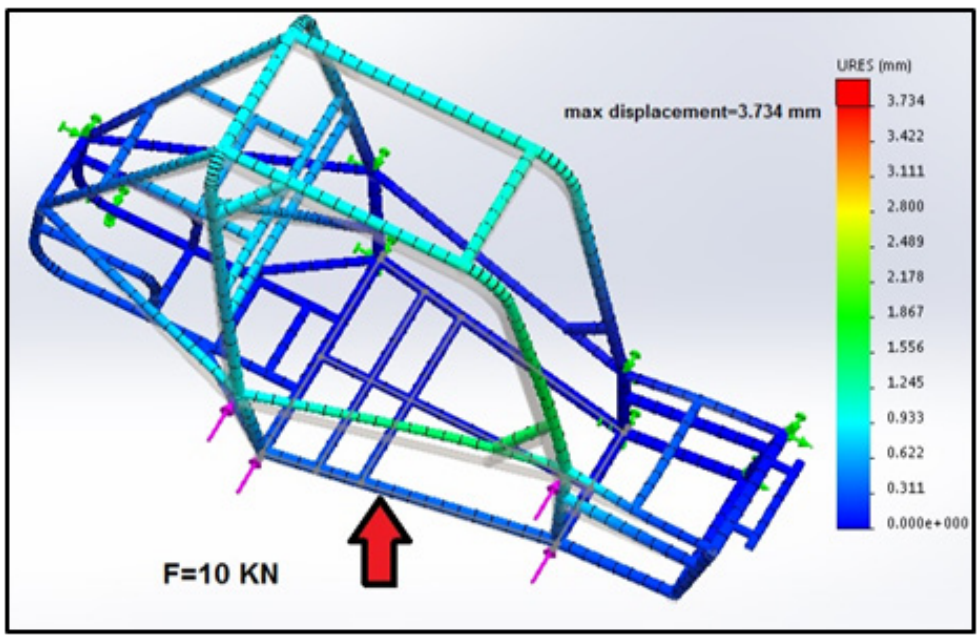

Fig. 4: Side impact stress analysis

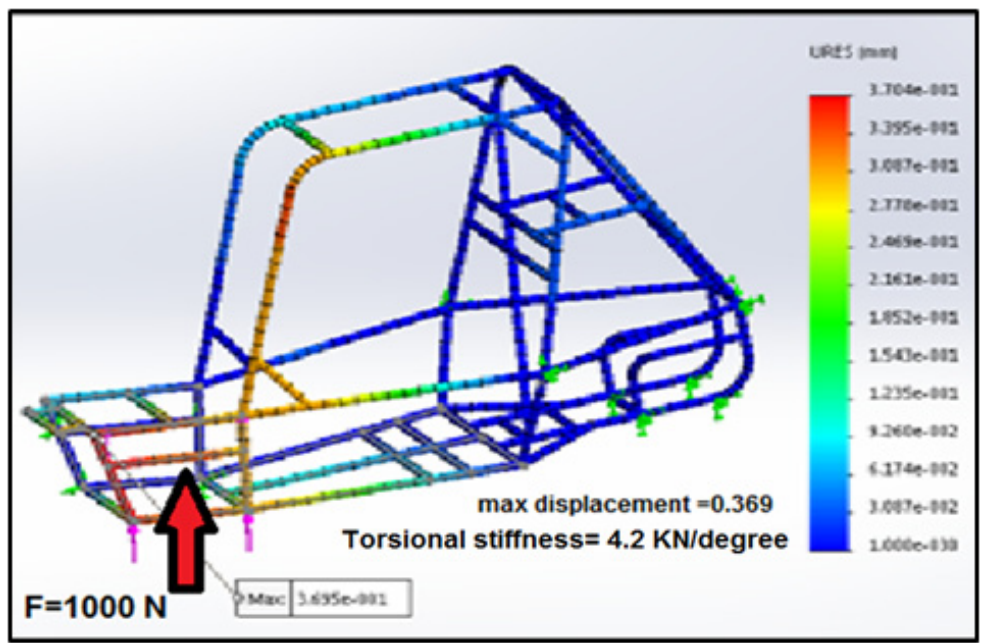

Fig. 5: Torsional stiffness estimation 


\section{SUSPENSION SYSTEM}

Suspension design calculations computed the proper parameters for the main vibration isolation components, the springs and struts parameters. Then these values were fine tuned to enhance vehicle ride, handling and safety characteristics. The second stage of suspension design compromises the optimization of suspension linkages (double A-Arms) through an intensive kinematic and dynamic analysis. Finally, the suspension forces deduced from the second stage were used to implement stress analysis for individual suspension components as well as the overall subsystem.

Suspension bounce natural frequency $(f)$, which is limited by human ride comfort zone and suspension static deflection, ride height, was chosen to be $1.2[\mathrm{~Hz}]^{[19]}$. Given the sprungmass $\left(m_{s}\right)$, the suspension stiffness $\left(k_{s}\right)$, and tire stiffness $\left(k_{t}\right)$ were initially calculated using equation (3), and in order to select the proper struts for the vehicle a quarter-car 2DOF model was used. Equations of motion of the model evolving suspension and tire stiffness and damping coefficients $\left(c_{s}, c_{t}\right)$ are represented in equations (4) and (5).

$$
f_{s}=\frac{{\frac{k_{s}}{m_{s}}}^{1 / 2}}{2 \pi}
$$

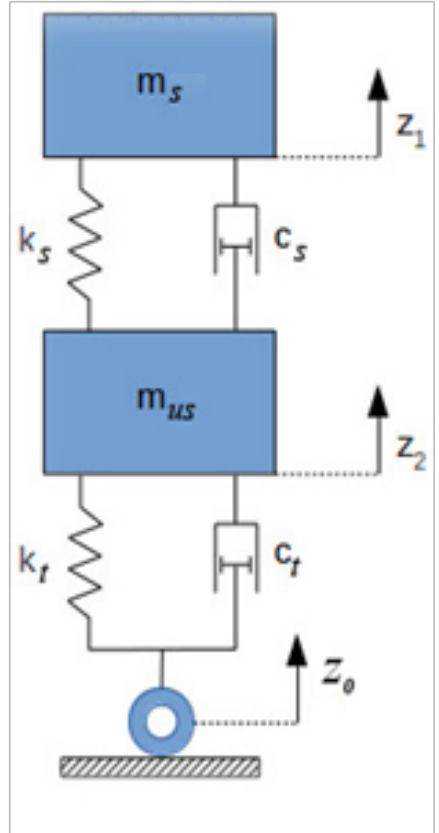

Fig. 6 (a)

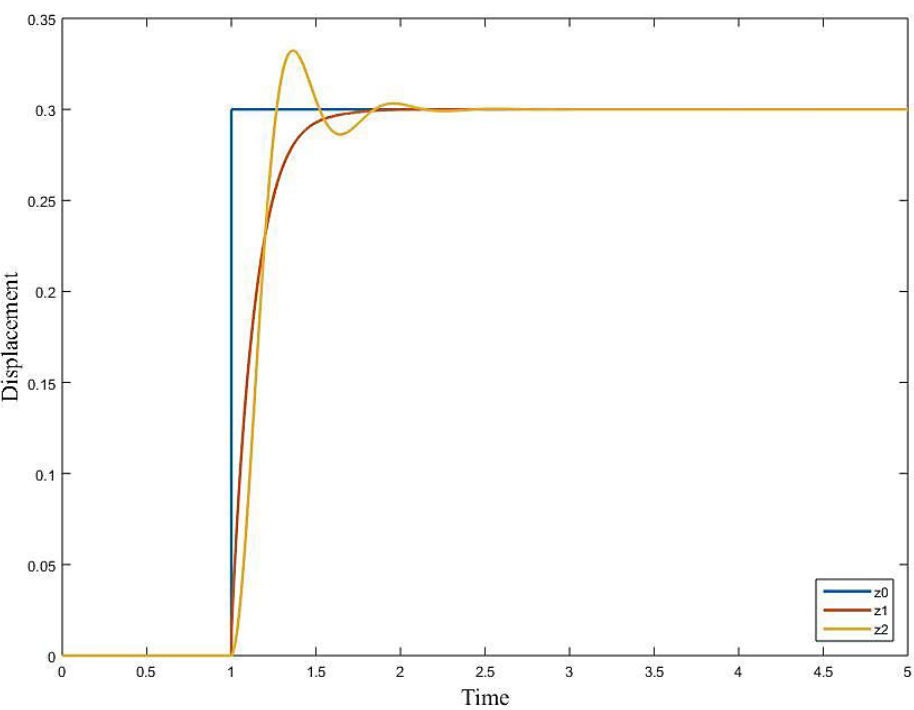

Fig. 6 (b)

Fig. 6: Quarter-car model and responses of sprungmass and unsprungmass due to step road input 


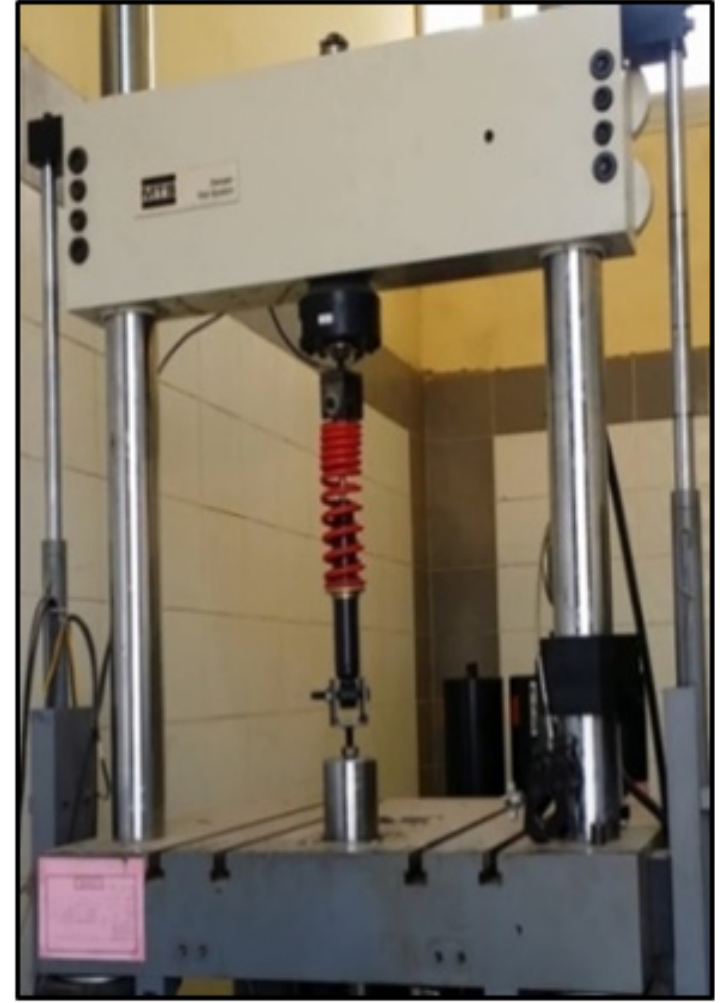

Fig.7 (a)

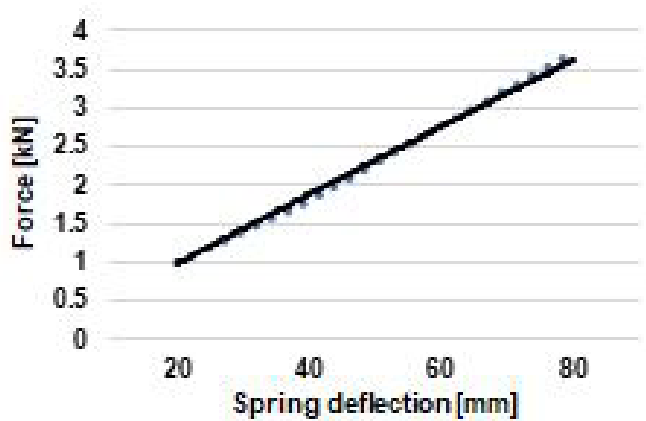

Fig. 7 (b)

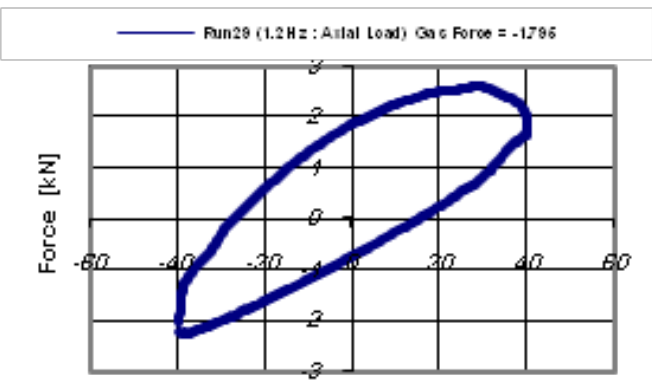

Strut displacement [mm]

Fig. 7 (c)

Fig. 7: Strut characteristics measurement and spring deflection

Anti-dive and anti-squat mechanisms were designed to further improve the ride comfort characteristics, Figure 8 . The angles were chosen so that $70 \%$ anti-dive and $70 \%$ anti-squat were achieved. Due to manufacturing challenging faced, the anti-dive and anti-squat mechanisms were discarded during manufacturing and the vehicle was built without those mechanisms ${ }^{[20]}$. Figure 9 shows the roll center analysis and the vehicle roll axis location. The angles and lengths of the control arms were chosen to minimize the roll center height. Suspension kinematic and dynamic analysis shown in Figure 10 was carried out to study the wheel angles' rate of change and to evaluate suspension forces. The kinematic relation between the wheel travel $\left(Y_{P}\right)$ and the camber change $(\alpha)$ is given by equation (6). The $(c 1, c 2 \ldots c 10)$ variables are the geometric dimensions of the upper A-Arm linkages, (L) is the spring solid length, $(\mathrm{r})$ is the tire radius, $(\mathrm{A})$ is the steering axis inclination angle, $(\mathrm{C})$ is the spindle angle, (B) and (q) are the upper and lower A-Arms angles with the vertical axis respectively as illustrated in Figure 10. Some of these variables are not included in the wheel travel equation but were used in its analytical derivation.

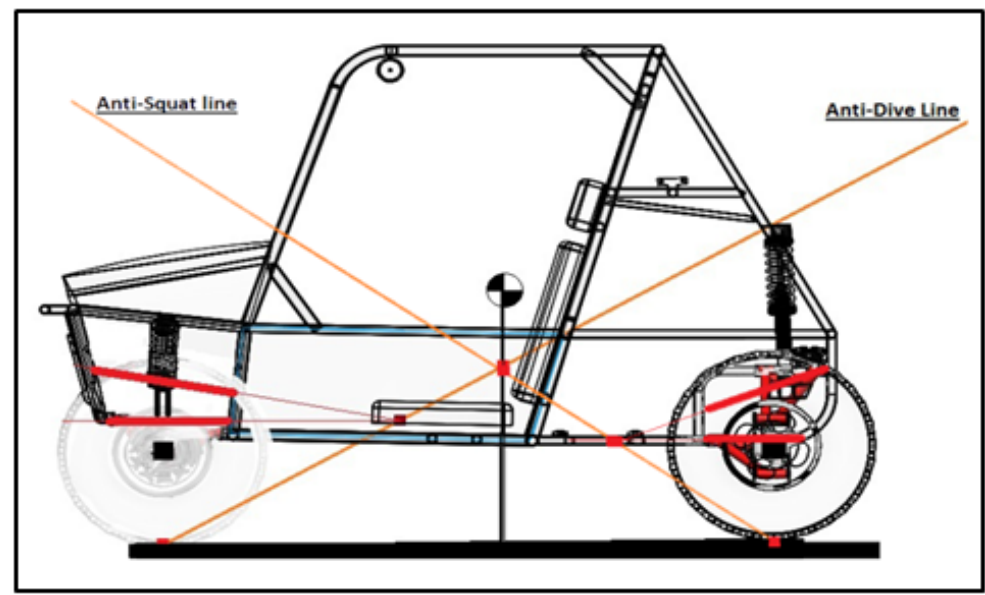

Fig. 8: Anti-dive and anti-squat mechanisms (70\%) 


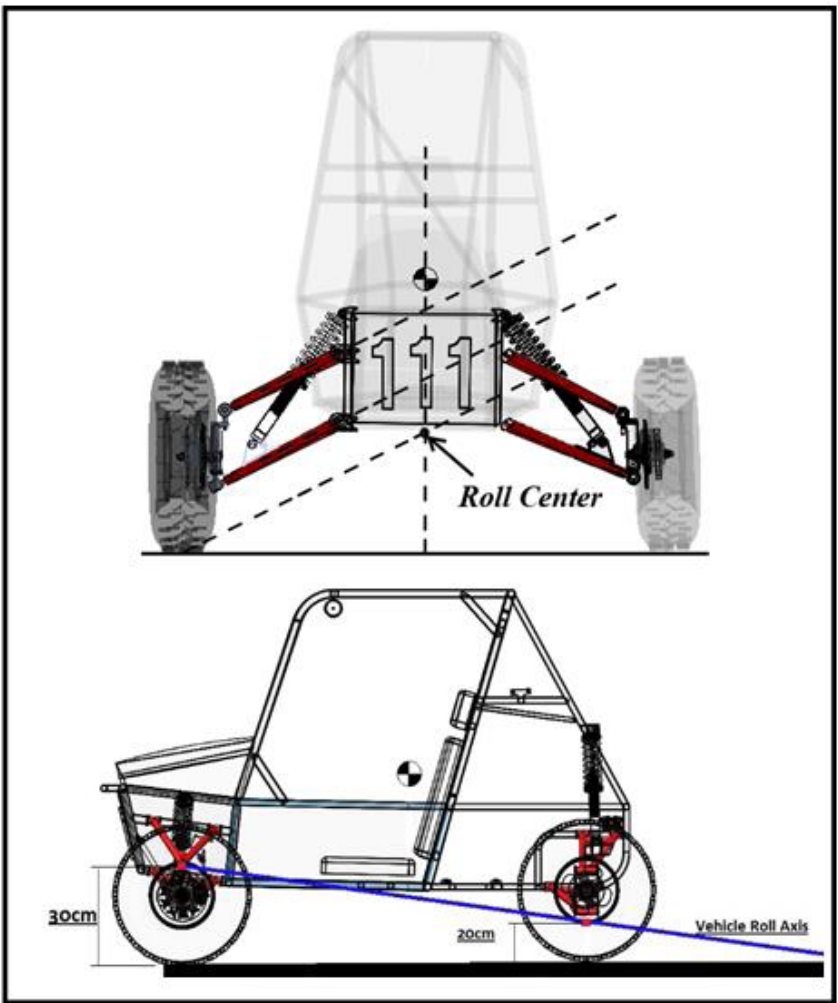

Fig. 9: Roll center / Axis analysis
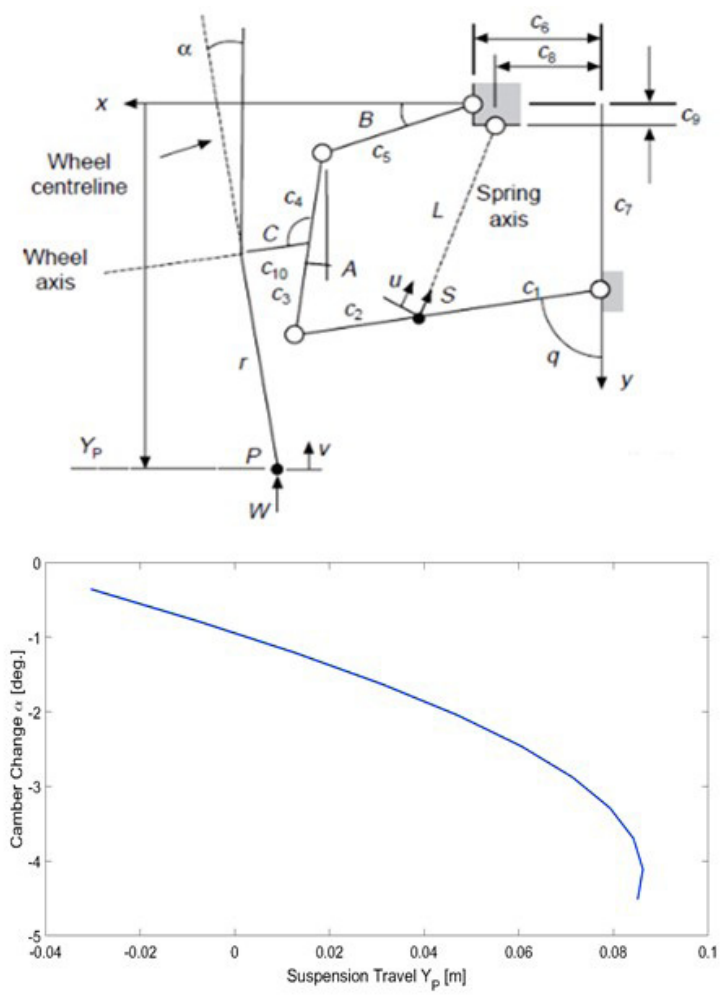

Fig. 10: Front A-Arm dimensions and camber change with travel

$$
Y_{p}=c 7+c 1 * c 2 * \cos q-c 3 * \cos A+c 10 * \sin \alpha+r * \cos \alpha
$$

The uprights used on this vehicle was designed and manufactured as an assembly of sheet metal shaping parts instead of being machined out of a single block due to the manufacturing cost limitations. During conceptual design phase, different upright and wheel centers designs were checked, analyzed and compared to the ones used on formula cars and similar ATV. The designed front/ rear uprights, front/rear wheel centers and suspension A-Arms were then analyzed using FEA capabilities of SOLIDWORKS $®$ as shown in Figure 11. According to the results of the FEA, the designed suspension components were safe.

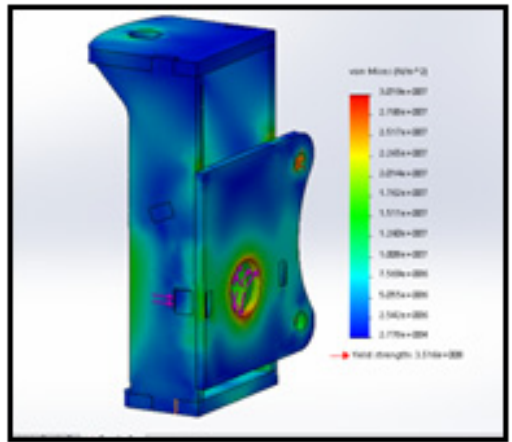

Fig. 11 (a)

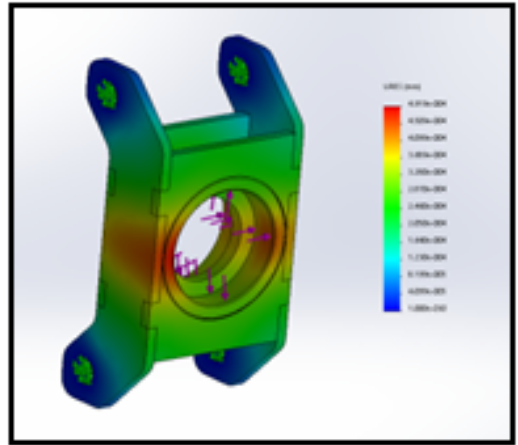

Fig. 11 (b)

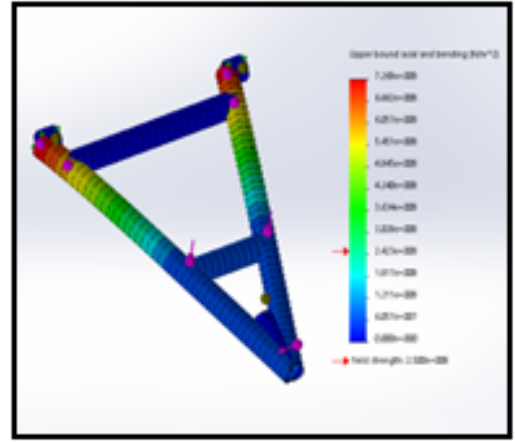

Fig. 11 (c) 


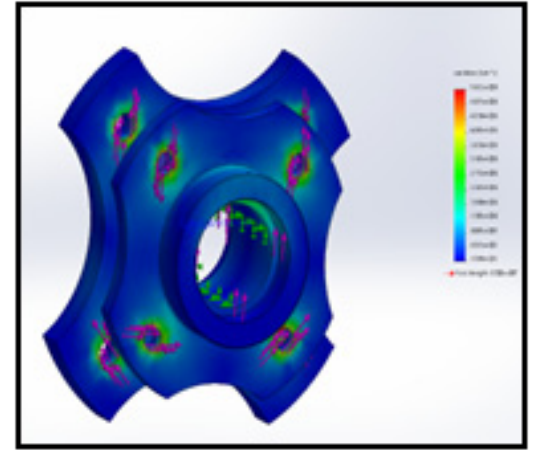

Fig. 11 (d)

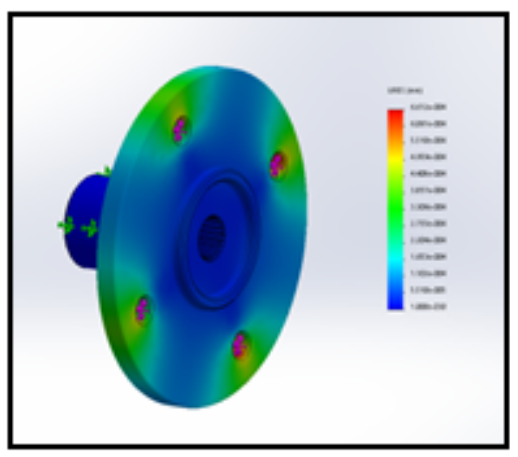

Fig. 11 (e)

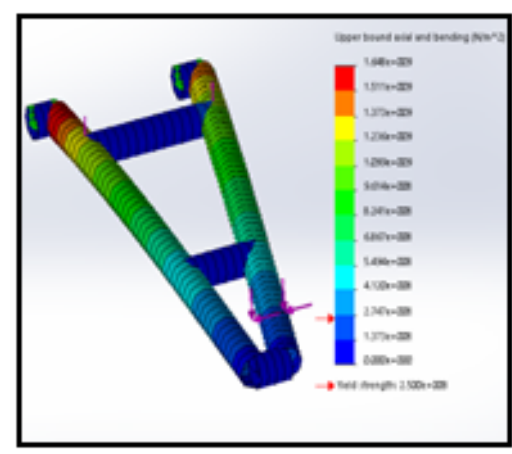

Fig. 11 (f)

Fig. 11: Suspension components stress analysis

\section{POWERTRAIN}

The selected powertrain was a rear engine-rear wheel drive, compromises a $305\left[\mathrm{~cm}^{3}\right]$, one cylinder, four stroke, air cooled, Briggs and Stratton OHV engine, producing 10 $[\mathrm{HP}]$ at $3800[\mathrm{rpm}]$ and $19[\mathrm{Nm}]$ at $2600[\mathrm{rpm}]$. A Polaris Magnum 500 Continuously Variable Transmission (CVT) was selected, providing an infinite number of transmission ratios that range from 4 to 0.7 while allowing stopping the vehicle without stopping the engine. To satisfy the design requirements, a custom made double stage reduction gearbox with 8.25 transmission ratio, shown in Figure 12, is coupled to the CVT, giving an overall transmission ratio

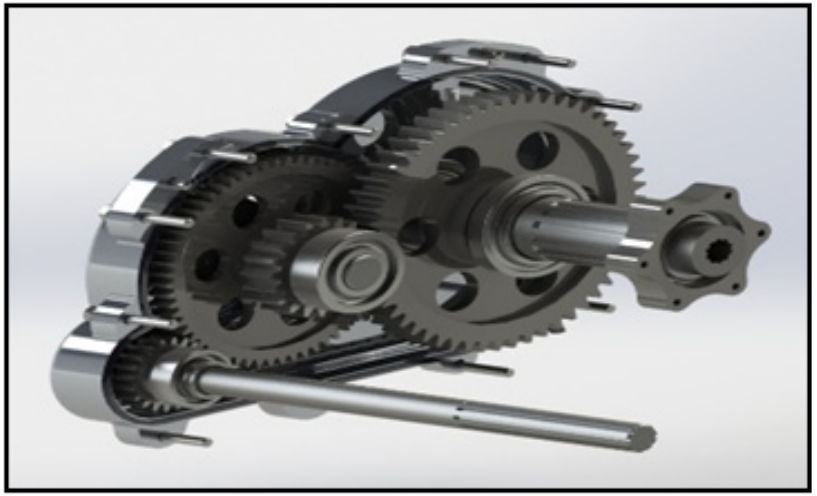

Fig. 12 (a) that ranges from 33 to 5.77, though maximizing traction and grade capabilities. Steel $1045 \mathrm{HR}$, Steel 20MnCr5, and Aluminum 7075 alloy were used in manufacturing of shafts, gears and casing of the custom made gearbox, respectively. FEA of gears, shafts and casing using SOLIDWORKS ${ }^{R}$ FEA tool showed that all of the individual parts and the overall system have high strength. The tractive effort delivered from the engine to propel the vehicle is shown in Figure 13. The rear drive shafts and joints were selected from the market and analyzed against stresses. The overall drivetrain layout is shown in Figure 14, and the vehicle overall design specifications are listed in Table 1.

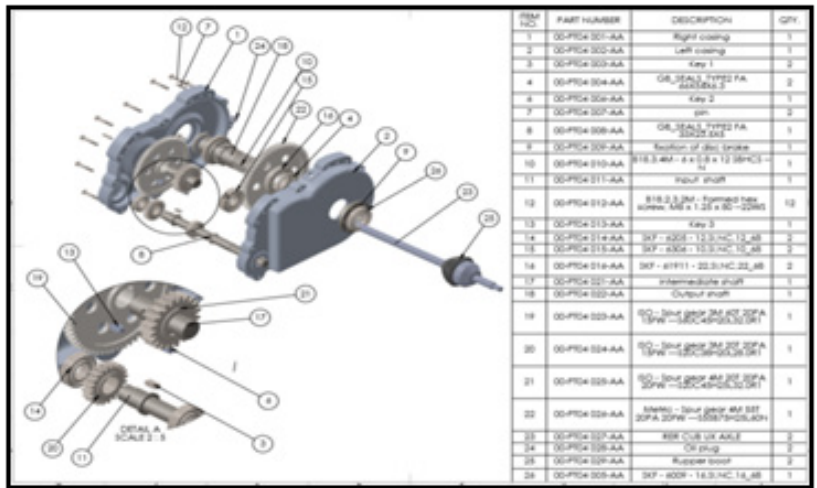

Fig. 12 (b)

Fig. 12: Custom made double stage reduction gearbox

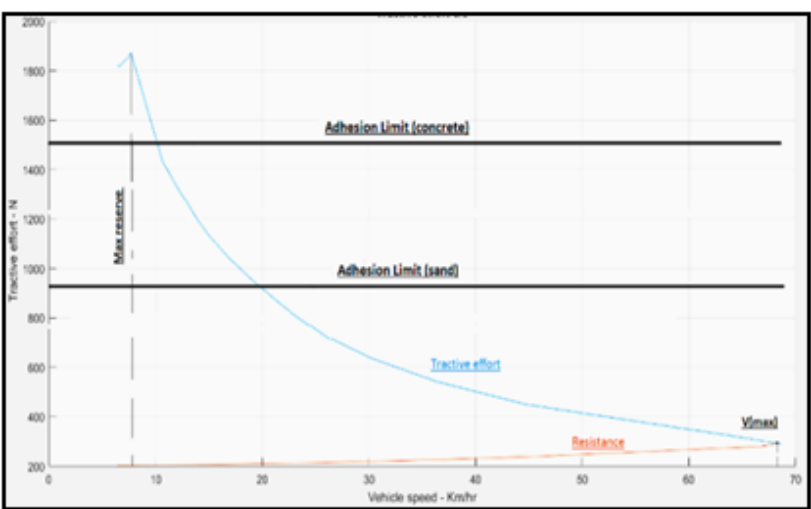

Fig. 13: Tractive effort performance curve

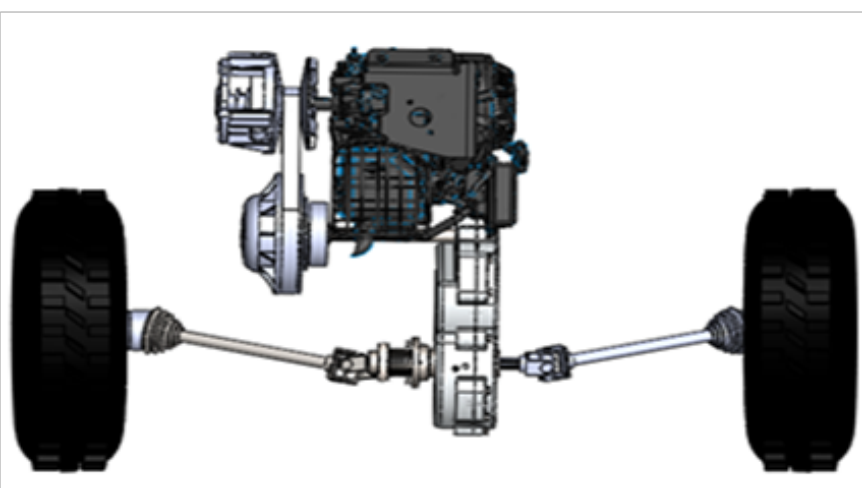

Fig. 14: Powertrain layout 
Table 1 : Vehicle parameters overall specifications

\begin{tabular}{|c|c|}
\hline Parameter & Description and value \\
\hline Engine & Briggs and Stratton 1445 series $305 \mathrm{~cm}^{3}$ Horizontal HC 19 [Nm] max torque, 3800 max rpm \\
\hline Maximum engine power & $10[\mathrm{HP}] @ 3800[\mathrm{rpm}]$ \\
\hline Maximum engine torque & $19[\mathrm{Nm}] @ 2600[\mathrm{rpm}]$ \\
\hline Transmission & CVT with reduction ratios from 4 to 0.7 \\
\hline Final drive & Custom made Double stage fixed reduction ratio 8.25 \\
\hline Overall transmission ratio range & From 33 to 5.77 \\
\hline Max Tractive effort & $1902[\mathrm{~N}]$ \\
\hline Tire dynamic radius & $0.28[\mathrm{~m}]$ \\
\hline Maximum speed & $65[\mathrm{Km} / \mathrm{h}]$ \\
\hline Gross vehicle weight & $340[\mathrm{Kg}]$ \\
\hline Payload & $60[\mathrm{Kg}]$ \\
\hline Gradeability & $65 \%$ \\
\hline Max. acc. & $5\left[\mathrm{~m} / \mathrm{s}^{2}\right]$ \\
\hline Approach /departure angle & $90[\mathrm{deg}] / 90[\mathrm{deg}]$ \\
\hline Overall length, width, and height & $2230[\mathrm{~mm}], 1600[\mathrm{~mm}]$, and $1480[\mathrm{~mm}]$ \\
\hline Ground clearance & $300[\mathrm{~mm}]$ \\
\hline Wheel base & $1650[\mathrm{~mm}]$ \\
\hline Wheel track & $\begin{array}{l}1400[\mathrm{~mm}] \text { front } \\
1245[\mathrm{~mm}] \text { rear }\end{array}$ \\
\hline
\end{tabular}

\section{STEERING SYSTEM}

In order to design and manufacture an efficient steering system, kinematic behavior of the system during its operation was considered. The rack-and-pinion steering mechanism was chosen to achieve the requirements of low cost, simplicity and reduced maintenance operations. The steering system was designed according to Ackerman principle $^{[21]}$; however, the design presented in this work was innovatively optimized mathematically. The steering mechanism used in the vehicle is the inverted Ackerman mechanism, where the rack is located in front of the front axle instead of being behind it as displayed in Figure 15 . The innovative idea presented here depends on optimizing the mechanism linkages' lengths mathematically so that the mechanism behaves following Ackerman condition. This work was based on the work presented in ${ }^{[22]}$.

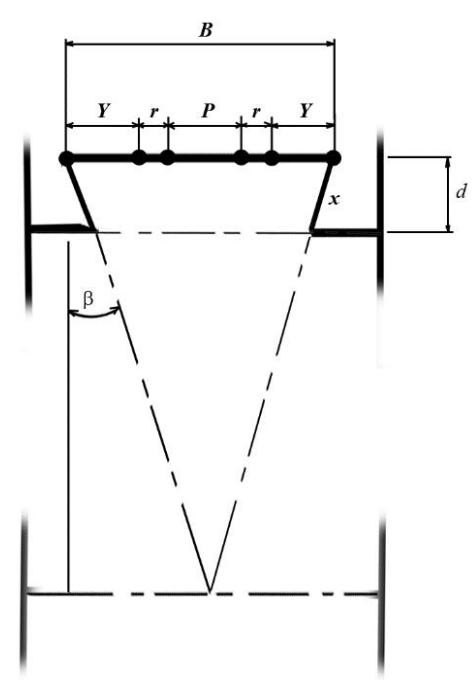

Fig. 15 : Inverted Ackerman mechanism dimensions 
Equation (7) relates the theoretical inner and outer wheel steering angles using Ackerman condition ${ }^{[21]}$. In this design, optimization of Ackerman linkages was achieved to follow the theoretical Ackerman condition. The mathematical representation that constrains the inverted Ackerman steering mechanism linkages is given inequation (8 and 9) and the equations parameters and variables definitions are listed with their corresponding values in Table 2.

Figure 16 shows the actual relation between the inner and outer wheel steering angles compared to the theoretical Ackerman relation.

$$
\begin{gathered}
\delta_{o}=\cot ^{-1}\left(\cot \delta_{i}+\frac{B}{L}\right) \\
Y^{2}=\left[\frac{B}{2}-\left(\frac{P}{2}+r-q\right)+x \sin \left(\delta_{i}-\beta\right)\right]^{2}+\left[d-x \cos \left(\delta_{i}-\beta\right)\right]^{2} \\
Y^{2}=\left[\frac{B}{2}-\left(\frac{P}{2}+r-q\right)+x \sin \left(\delta_{i}-\beta\right)\right]^{2}+\left[d-x \cos \left(\delta_{i}-\beta\right)\right]^{2}
\end{gathered}
$$

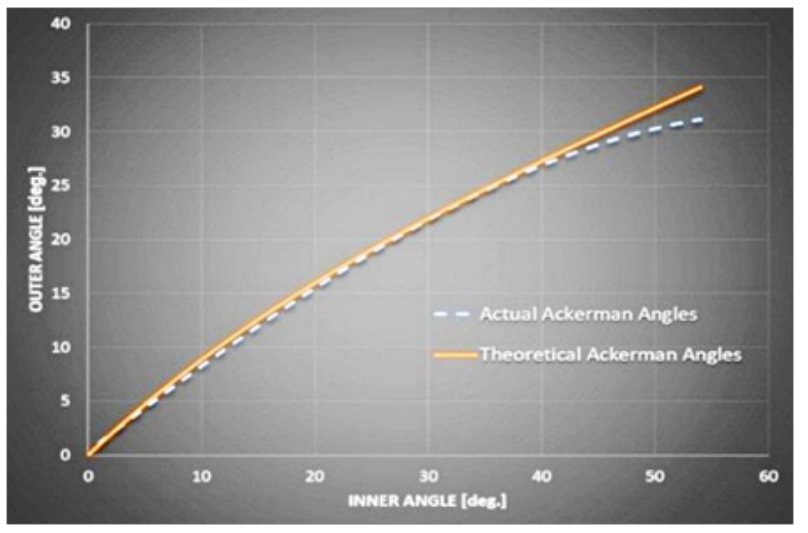

Fig. 16: Actual versus theoretical Ackerman angles

A steering quickener with a ratio of 1:2 was designed and manufactured, Figure 17, to be added to the steering mechanism to, optionally, reduce the steering ratio to 6.14:1. A steering column with double universal joints was used to control the steering wheel inclination in order to achieve adjustable driving position according to ergonomics requirements. The approximate kingpin torque, and driver forcewere calculated using equations 10 and 11 respectively, equation parameters and variables definitions are listed with their corresponding values in Table 2. Steering system parameters were obtained after extensive geometric and mathematical analyses.In the final design step, all steering system components' stresses were analyzed using SOLIDWORKS ${ }^{\circledR}$ FEA simulation. The results and the experimental tests showed that all the steering system components are safe.

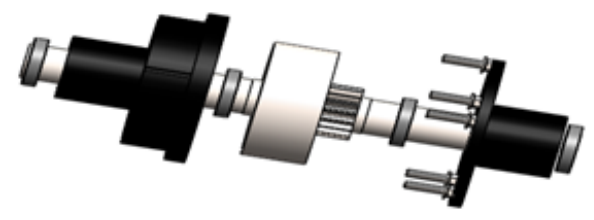

Fig. 17 : Steering quickener

$$
\begin{aligned}
& M_{L}=G * \mu \sqrt{\frac{b^{2}}{8}+l^{2}} \\
& \left(F_{d}\right)=\frac{M_{d}}{D_{s w}}
\end{aligned}
$$


Table 2: Steering system parameters and variables

\begin{tabular}{|c|c|c|}
\hline Parameter & Value & Description \\
\hline Inner angle $\left(\delta_{\mathrm{i}}\right)$ & $\approx 29.5^{\circ}$ & From design \\
\hline Outer angle: $\left(\delta_{\mathrm{o}}\right)$ & $\approx 34.5^{\circ}$ & Evaluated analytically \\
\hline Ackerman angle $(\beta)$ & $\approx 22.25^{\circ}$ & Evaluated analytically \\
\hline Wheel base (L) & $1650[\mathrm{~mm}]$ & From design \\
\hline Distance between left and right kingpin centerline (B) & $1350[\mathrm{~mm}]$ & From design \\
\hline Rack casing length $(\mathrm{P})$ & $250[\mathrm{~mm}]$ & For the used steering gearbox \\
\hline Rack ball joints center to center distance $(p+2 r)$ & $450[\mathrm{~mm}]$ & For the used steering gearbox \\
\hline Steering arm length $(\mathrm{x})$ & $110[\mathrm{~mm}]$ & Optimization output \\
\hline Rack travel (q) & $35.5[\mathrm{~mm}]$ & Optimization output \\
\hline Tie rod length $(\mathrm{Y})$ & $410[\mathrm{~mm}]$ & Optimization output \\
\hline Distance between front axis and rack center axis (d) & $168.8[\mathrm{~mm}]$ & $\beta$ Optimization output \\
\hline Steering gearbox ratio & $6.14: 1$ & From design \\
\hline Turning radius $(\mathrm{R})$ & $4[\mathrm{~m}]$ & From design \\
\hline Vehicle weight on steered axle( G) & $156.5[\mathrm{Kg}]$ & From design \\
\hline Coefficient of friction $(\mu)$ & 0.2 & On sand \\
\hline Nominal width of Tire-print (b) & $171.5[\mathrm{~mm}]$ & From design \\
\hline Scrub radius (l) & $40.52[\mathrm{~mm}]$ & From design \\
\hline Steering wheel diameter $\left(\mathrm{D}_{\mathrm{sw}}\right)$ & $250[\mathrm{~mm}]$ & From design \\
\hline kingpin torque $\left(\mathrm{M}_{\mathrm{L}}\right)$ & $22.5[\mathrm{Nm}]$ & Evaluated analytically \\
\hline Driver force $\left(\mathrm{F}_{\mathrm{d}}\right)$ & $29[\mathrm{~N}]$ & Evaluated analytically \\
\hline Driver torque $\left(\mathrm{M}_{\mathrm{d}}\right)$ & $3.65[\mathrm{Nm}]$ & Evaluated analytically \\
\hline
\end{tabular}

\section{CONCLUSION}

Through the journey of the design and manufacturing of the presented ATV, all of the objective goals were met. The design and manufacturing of a reliable lightweight vehicle that could be used in military and civilian applications was achieved. A competitive vehicle was designed. Such a challenging practical project enhanced theoretical analysis capabilities and practical experience. The vehicle design was explored in this report. Starting from design objectives, passing through system integration, design concepts, individual subsystems design, individual parts design, and ending with production and testing, this work was organized to highlight the main aspects succinctly.

The vehicle design was broken down into several systems. During the design phase, integration between the subgroups was facilitated using the software integration capabilities. During the manufacturing phase, a coding system was implemented for integrating parts, assemblies, and subassemblies. Individual parts, subsystems, and the overall system were tested experimentally. The vehicle was designed, built, and tested successfully.

\section{ACKNOWLEDGMENTS}

Great sincere goes to the Military Technical College
(MTC) administrationfor supporting this project financially, as well as the Vehicles Department Industrial Complex for using their facility during production and manufacturing period. In addition, we would like to appreciate the MTC Automotive Engineering Department faculty members for their generous knowledge and support.

\section{REFERENCES}

[1] https://www.bajasae.net/

[2] Shukla, P., Joshi, K., Rastogi, U., and Moola, A., "Design Analysis and Simulations of Components of an All-Terrain Vehicle," SAE Technical Paper 2019-28-0049, 2019, doi:10.4271/2019-28-0049.

[3] Rishabh Hain, and Ranjit P. S., "Design of a Drivetrain for Sae Baja Racing Off-Road Vehicle," International Journal of Advanced Engineering, Management and Science (IJAEMS), ISSN: 2454-1311, vol-1, Issue- 4, July 2015.

[4] Sandeep Chaudhary et al., "Design Analysis and Fabrication of M_BAJA ATC 2020,'International Journal of Modern Communication Technologies and Research, IJMCTR,ISSN: 2321-0850, vol-8, Issue-5, May 2020.

[5] Yogesh Chandra, "Design, Analysis and Optimization of a BAJA-SAE Frame," International Journal of Science and Research (IJSR), Volume 9 Issue 2, February 2020, ISSN: 2319-7064, doi: 10.21275/SR20208233756.

[6] Owens, A., Jarmulowicz, M., and Jones, P., "Structural Considerations of a Baja SAE Frame," SAE Technical Paper 2006-01-3626, 2006, doi:10.4271/2006-01-3626.

[7] Sharma, Y., Garg, R., Bhargava, R., Singh Deo, A. et al., "Design and Development of Single Seat, Four Wheeled All-Terrain Vehicle for Baja Collegiate Design Series," SAE Technical Paper 2015-01-2863, 2015, doi:10.4271/2015-01-2863. 
[8] Rishabh Jain, P S Ranjit, "Design of a Drivetrain for SAE Baja Racing Off-Road Vehicle," International Journal of Advanced Engineering, Management and Science (IJAEMS), Vol-1, Issue-4, July- 2015, ISSN: 2454-1311.

[9] AkshayBodake, AdityaKhairnar, Ashraf Pathan, "Design and Development of a Powertrain System Scope of BAJA Vehicle," International Journal of Advance Engineering and Research Development, Volume 5, Issue 12, December -2018, e-ISSN (O): 2348-4470

[10] Perez, S and Bachman, J., "Design of Baja SAE Gearbox for Optimal Performance and Minimum Weight," SAE Technical Paper 2020-32-2311, 2020, https://doi.org/10.4271/2020-32-2311.

[11] Akshay G Bharadwaj, Sujay M., Lohith E., Karthik S., "Design, Analysis, Simulation and Validation of Suspension System for an Electric All-Terrain Vehicle (ATV)," International Journal of Innovative Research in Science, Engineering and Technology, Vol. 5, Issue 12, December 2016, ISSN(Online) : 2319-8753.

[12] NayanDeshmukh, Vivek Singh Negi, AmitDeshpande, "Design of Double Wishbone Suspension System of BAJA Vehicle," International Journal of Advance Engineering and Research Development, Volume 4, Issue 12, December -2017, e-ISSN (O): 2348-4470.

[13] AkshayPawar, and SurajZambare, "Design of Steering System for All Terrain Vehicle," International Research Journal of Engineering and Technology (IRJET), Volume: 05 Issue: 03 | Mar-2018, e-ISSN: 23950056 .

[14] S. Neelakrishnan, Kowshik T, Krishnakumar G, Bharathi Mohan M P., "Analysis and Improvement of the Steering Characteristics of an
ATV.," Int. Journal of Engineering Research and Application, Vol. 7, Issue 5, ( Part -4) May 2017, pp.18-25, ISSN : 2248-9622.

[15] Alfred Showers and Ho-Hoon Lee, "Design of the Steering System of an SELU Mini Baja Car," International Journal of Engineering Research and Technology (IJERT), Vol. 2 Issue 10, October - 2013, ISSN: 22780181.

[16] Asad Khan, Mayan Kansal, Rahul Sindhu, VasuBhardwaj, “Optimized Rack and Pinion steering system with Steering Stops incorporation over Rack-Casing Assembly for a BAJA SAE All-terrain Vehicle," American International Journal of Research in Science, Technology, Engineering and Mathematics, 2019, ISSN (Online): 2328-3580.

[17] Lilley, R., Asfoor, M. Sh., Santora, M., Cordon, D. et al., "Design of the University of Idaho Formula Hybrid Vehicle,"SAE Technical Paper 2015-01-0414, 2015, doi:10.4271/2015-01-0414.

[18] Kumar, S., Biomechanics in Ergonomics Book, ch2, 2nd Ed., CRC Press, ISBN: 9780849379093, NY, USA, 2007.

[19] Wong, J. W., Theory of Ground Vehicles Book, ch7, 2nd Ed., John Wiley and Sons Inc., ISBN: 0471354619, NY, USA, 1993.

[20] Gillespie, T. D., Fundamentals of Vehicle Dynamics Book, WarrendaleSAE, 1992, Pa., USA, ISBN - 1560911999.

[21] Koladia, D., "Mathematical Model to Design Rack and Pinion Ackerman Steering Geometry,'International Journal of Scientific and Engineering Research (IJSER), vol. 5, no. 9, pp.: 716-720, Sep. 2014.

[22] Jazar, R., Vehicle Dynamics - Theory and Applications Book, ch6, 3rd Ed., pp.279-446, ISBN: 978-3-319-53440-4, Springer International Publishing AG, Cham, Switzerland, 2017. 